\title{
Revista Colombiana de

\section{0 años de la Revista Colombiana de Cardiología}

\section{0 years of the Colombian Journal of Cardiology}

\section{Darío Echeverri (Editor)}

\begin{abstract}
Servicio de Hemodinamia e Intervencionismo Cardiovascular, Fundación Cardioinfantil - Instituto de Cardiología, Bogotá, Colombia
\end{abstract}

Recibido el 18 de enero de 2016; aceptado el 19 de enero de 2016

\section{Expresar la felicitación...}

Este décimo tercer aniversario de la Revista es motivo de felicidad y orgullo. En nombre de los Comités Científicos y del grupo administrativo, extendemos nuestras sinceras felicitaciones a la Sociedad Colombiana de Cardiología y Cirugía Cardiovascular y a todos sus miembros, por hacer que la Revista permanezca como el órgano oficial de difusión de la cardiología del país. Un acontecimiento tan memorable, no puede transcurrir sin felicitar a todas aquellas personas que han pasado por la Revista y han permitido tener los resultados que hoy podemos disfrutar.

El excelente trabajo del Dr. Jorge León Galindo durante los casi 30 años pasados, justifica claramente esta celebración. La fortaleza y el prestigio que ha alcanzado la Revista durante estos años son apenas un silencioso homenaje a sus esfuerzos.

En la actualidad, la Revista cuenta con un excelente equipo humano conformado por dirección administrativa, coordinación editorial, auxiliar de revista, corrector de estilo, soporte tecnológico y grupo de traducción. Se encuentra enmarcada en el Sistema de Gestión de la Calidad de la Sociedad Colombiana de Cardiología, bajo la norma ISO 9001: 2008 y certificada por Bureau Veritas. Publica un volumen al año, cada uno con seis números de publicación bimestral. A la fecha se han publicado 22 volúmenes, 156 números y más de 2.100 artículos. El perfil del lector son cardiólogos clínicos, cirujanos cardiovasculares, epidemiólogos, hemodinamistas, electrofisiólogos, ecocardiografistas, urgenciólogos, médicos internistas y

Correo electrónico: decheverri@cardioinfantil.org enfermeras, y está disponible en las principales instituciones de salud pública y privada, universidades y bibliotecas del país.

En los últimos dos años se ha hecho un gran esfuerzo para fortalecer el portal web de la Revista. Se han recibido más de 3.500 visitas mensuales, de visitantes de más de 50 países. Descargan cerca de 7.000 artículos científicos al mes, en formato pdf, multiplicándose por cinco solamente en el último año para llegar a un total de 70.000 artículos descargados a la fecha. Llegan a la web de la Revista a través de sistemas Chrome, Safari, Firefox, Internet Explorer, Opera y YaBrowser. De otro lado, en la página web está en construcción el «proyecto micrositios» que ofrecerá actualización, capacitación y educación en las principales áreas de Cardiología y Cirugía cardiovascular, noticias científicas y cubrimiento de congresos.

Así mismo, la Revista está indexada en bases de datos reconocidas como: ScienceDirect, Publindex, LILACS, Scopus y SciELO, y en redes sociales como Facebook, Twitter, Linkedln y YouTube.

Estos logros y la gran visibilidad actual de nuestras investigaciones y de sus autores obedece en gran parte a la vinculación con la Editorial Elsevier. El apoyo incondicional de las últimas dos Juntas Directivas de la Sociedad en lograr esta vinculación, han sido fundamentales para el crecimiento de la Revista. El trabajo por artículo, favorece la publicación del «avance online», de modo que los autores pueden enviar sus manuscritos y conocer su estado durante todo el proceso hasta el momento de su aceptación; se cuenta con un apoyo permanente en el proceso de indexación y se facilita la lectura en línea desde cualquier dispositivo móvil, así como la distribución digital. 
Nuestra gran intención es publicar números extraordinarios con consensos, guías y estados del arte. Los simposios anuales han tenido un porcentaje de satisfacción cercano al $100 \%$, resultados que serían imposibles sin el apoyo de la industria de medicamentos (AstraZeneca, Sanofi, Bayer, Pfizer, Novartis, Boehringer Ingelheim, Biotoscana, Aspen, Roche, Amgen, entre otros) y de dispositivos (Terumo). Así mismo, se está a la búsqueda de nuevos aliados, al igual que a la exploración de nuevos mercados.
Independientemente de lo que depare el futuro, espero que Dios nos guie para continuar creciendo y obtener los logros esperados. La Revista es el mayor activo de la Sociedad Colombiana de Cardiología y Cirugía Cardiovascular. Debemos protegerla de las amenazas, cuidarla de las agresiones, reconocer sus fortalezas y permitir que crezca en medio de las mejores oportunidades disponibles. Llevemos a la Revista Colombiana de Cardiología en el corazón. Apoyémosla y celebremos muchos cumpleaños más en el futuro. 